\title{
Optimization of Injection Molding of Automotive Plastic Horn Cover Part Using Taguchi Method and Reverse Engineering
}

\author{
YONGSUN LEE ${ }^{1}$, JINRAE CHO ${ }^{2}$, SEONGRYEOL HAN ${ }^{*}$ \\ ${ }^{1}$ Kongju National University, Department of Optical Engineering \& Metal Mold, 1223-24, Cheonan-daero, Seobuk-gu, \\ Cheonan-si, Chungcheongnam-do, Republic of Korea \\ ${ }^{2}$ Hongik University, Department of Naval Architecture and Ocean Engineering, 2639, Sejong-ro, Jochiwon, Sejong-si, \\ Republic of Korea
}

\begin{abstract}
The aim of the paper consisted in the development of an injection mold for plastic horn cover parts in commercial vehicles. Three mold types were designed in anticipation of the structure and quality of molds, and injection molding numerical analyses were conducted for the three types of molds. One mold type was selected in consideration of the resin flow patterns inside the mold, surface quality, and final deflection amount of the horn cover. To perform optimal injection molding using the selected mold, optimization of injection molding parameters was performed using the Taguchi method, one of the designs of experiment (DOE) and ANOVA methods. As a result, it was confirmed that the deflection amount of the molding under optimal molding parameters decreased by about $34.3 \%$ compared to the deflection amount before optimization of the molding parameters. Based on these encouraging results, the previously selected mold type was actually manufactured. The horn cover was molded using the obtained optimal injection molding parameters to the manufactured mold. To verify the precision of the molded horn cover, the deflection amount of the molding was measured with a 3D scanner. The deflection amount of the horn cover was estimated to be about $11 \%$ to $43 \%$ larger for each measurement position than the deflection amounts in the analysis results. The manufactured mold was revised to solve the problem that the deflection amount of the actual molding is larger than the deflection amount predicted by injection molding analysis. The dimensions and surface quality of the horn cover with a revised mold were satisfactory.
\end{abstract}

Keywords: injection molding, plastic horn cover, design of experiment, Taguchi method

\section{Introduction}

Among the various manufacturing methods, injection molding using plastic material has the advantage of making even complex shapes into a one-time process. Also, it is specialized for the mass production of products with the identical shape and dimensions and is actively used in our daily lives and the industrial sector [1-6].

Despite these advantages, a factor that hinders applying plastic injection molding to more areas is that, compared to other production methods, it is quite difficult to obtain dimensional precision of plastic molding product dimensions in a short time because, for precise injection molding, various injection parameters must be adequately harmonized. Optimal injection molding requires correct plastic materials, accurate mold design and fabrication, and accurate control of injection molding parameters.

Assuming that accurate design and fabrication of the mold have been carried out, the optimization of various injection molding parameters is essential for optimal injection molding. Injection molding parameters necessary for injection molding include injection time, injection pressure, mold temperature, and cooling time. However, it is almost impossible to optimize these parameters quickly. Many plastic molding production companies spend considerable money and time after mold porduction on injection molding testing to establish optimal parameters. Accordingly, the use of more scientific techniques to determine the appropriate processing parameters is urgently required [7].

*email: srhan@kongju.ac.kr 
The Taguchi method, one of the design of experiment (DOE) method, is actively being utilized as a recommended production-site-friendly method for effectively and quickly optimizing various injection molding parameters [8-10]. The Taguchi method is a proven optimization method applied in the injection molding field and other industries. In addition, in the area of injection molds, the use of $3 \mathrm{D}$ scanning, a reverse engineering methods, continues to be expanded to develop fast, accurate injection molds.

A lot of research has been done on how to optimize injection molding. Experiments have been conducted to determine the effect of injection molding parameters on the defects of transparent injection molding parts used in air conditioners. A grey relational analysis (GRA) was generated using the Taguchi method to determine the optimal injection molding parameters [11]. Artificial neural network (ANN) and particle swarm optimization (PSO) techniques were used to predict the optimal injection molding processes for bi-aspheric lenses [12]. Effects of process parameters on injection molding of pmc cam bush was investigated. The researchers also wanted to improve the quality of cam bush by performing experiments using the Taguchi method and optimizing the process parameters using GRA [13]. A method was proposed to improve the quality dimension of component volume change by combining artificial neural network and genetic algorithm techniques (ANN/GA) [14]. Gas injection molding simulation was utilized to reduce gas injection production time and cost and obtain optimal parameter settings, and was implemented in experiments with full factorial design [15]. Taguchi method was used to achieve optimal injection parameters according to the quality characteristics of samples made from polypropylene-nanoclay-gigantochloa scortechinii fibers [16]. Various defects were addressed by optimizing injection molding process parameters using finite element and Taguchi methods in die slide injection moldings. The validity of the study was verified using ANOVA on the derived optimal value [17]. Taguchi method and desirability function hybridization approach were used to optimize injection molding process parameters [18]. Taguchi method was applied to optimize the injection molding process parameters of the isal-glass fiber hybrid biocomposite [19]. Numerical analysis was performed in consideration of non-Newtonian motion, heat transfer, and structural analysis to predict mold deflection occurring in the injection molding charging process. An experimental design method based on the Taguchi method was introduced to understand the effects of polymer resins, mold temperature, and flow rate on mold deflection [20]. Warpage optimization by finite element analysis, response surface methodology, and genetic algorithms were studied. A predictive model for the warpage was established using RSM. The response surface model was combined with GA to find optimal process parameter values [21]. Before making the injection mold, injection molding numerical analysis and machine learning were conducted to predict the warpage of automotive parts [22]. 3D scan operation was carried out to create a product model and use it as an injection mold design data before making an injection mold [23-25].

Most of the mentioned injection molding studies using the Taguchi method have focused on obtaining optimal injection molding parameters for injection molding processes and on verifying optimal molding parameters only with injection molding analysis. In addition, 3D scanners, commonly used in product development or benchmarking, were used for dimensional precision verification of products molded under optimized injection molding parameters, and the verification data were used for modifications to actual molds. In other words, most studies are missing the process of actually fabricating molds and validating them by applying injection molding parameters optimized by the Taguchi method. Therefore, this study proposes an efficient and modern injection molding process optimization and suggests a new injection mold design and modification method using a 3D vision system.

\section{Materials and methods}

\subsection{Horn cover and material}

Figure 2 shows a horn cover mounted on a commercial truck steering wheel. At the front center of the cover, there is a space for attaching the logo. The back of the cover has a very complex shape, 
unlike the front. There is a storage space for the airbag case in the rear center of the horn cover, and nine snap fits for assembly with the steering wheel. The back outer part has many ribs to reinforce the horn cover. The size of the horn cover is approximately 180 (horizontal) $\times 200$ (vertical) $\times 80$ (height) $(\mathrm{mm})$. The horn cover is made of TOSI 818 35D from Mitsubishi Chemical, an elastomer resin. Table 1 lists the mechanical properties of the polymer; the injection molding parameters recommended by Mitsubishi Chemical are given in Table 2.

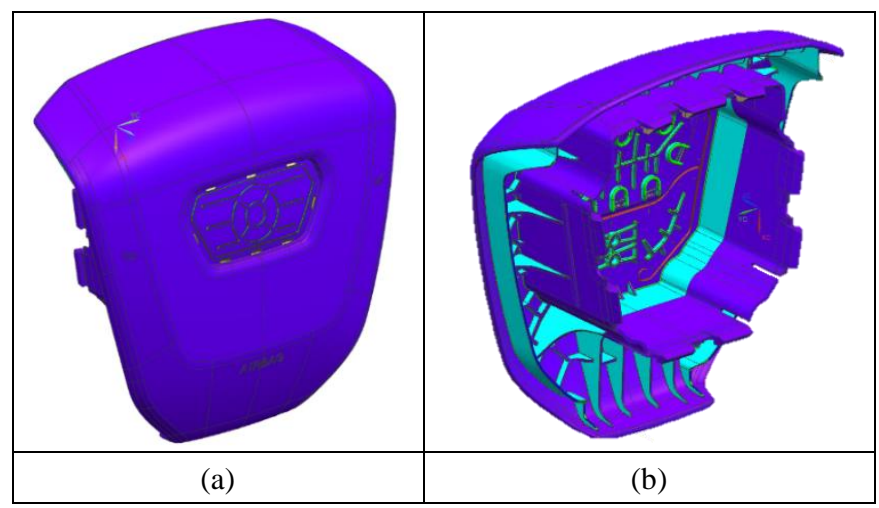

Figure 2. Horn Cover: (a) front (b) back

Table 1. Mechanical properties of TOSI 818 35D

\begin{tabular}{|c|c|c|}
\hline Items & Unit & Values \\
\hline Elastic modulus & $\mathrm{MPa}$ & 178 \\
\hline Poisson's ratio & - & 0.44 \\
\hline Shear modulus & $\mathrm{MPa}$ & 61 \\
\hline Coefficient of thermal expansion & $1 /{ }^{\circ} \mathrm{C}$ & $1.205 \mathrm{e}-05$ \\
\hline Melt density & $\mathrm{g} / \mathrm{cm}^{3}$ & 0.78516 \\
\hline Transition temperature & ${ }^{\circ} \mathrm{C}$ & 125 \\
\hline Measured MFR & $\mathrm{g} / 10 \mathrm{~min}$ & 18 \\
\hline
\end{tabular}

Table 2. Recommended injection molding condition of TOSI $81835 \mathrm{D}$ (unit: ${ }^{\circ} \mathrm{C}$ )

\begin{tabular}{|c|c|}
\hline Process parameters & Values \\
\hline Mold temperature & 40 \\
\hline Melt temperature & 200 \\
\hline Ejection temperature & 90 \\
\hline
\end{tabular}

\subsection{Injection molding analysis}

Figure 3 shows three injection molds designed to mold horn covers. In the type 1a model, a hot runner with a diameter of $\varnothing 8$ and a hot gate with a diameter of $\varnothing 3$ are located at the front center of the mold. Also, two valve gates with a diameter of $\varnothing 4$ are located to suppress weldline generation and reduce injection pressure on the lower side of the mold. The valve gate is connected to an elephant gate with a diameter of $\emptyset 2$. The type $2 \mathrm{~b}$ model has three valve gates with diameter of $\varnothing 4$ on the mold's lower front, lower left, and right sides. Type $3 \mathrm{c}$ has three valve gates with diameter of $\varnothing 4$ on the lower back, left, and right. The valve gates of type $2 \mathrm{~b}$ and type $3 \mathrm{c}$ also have elephant gates of $\varnothing 2$ diameter, the same as type 1a. Also, straight cooling channels with diameter $\varnothing 8$ and baffle cooling channels with diameter $\varnothing 15$ were designed for the fixed half and moving half. 


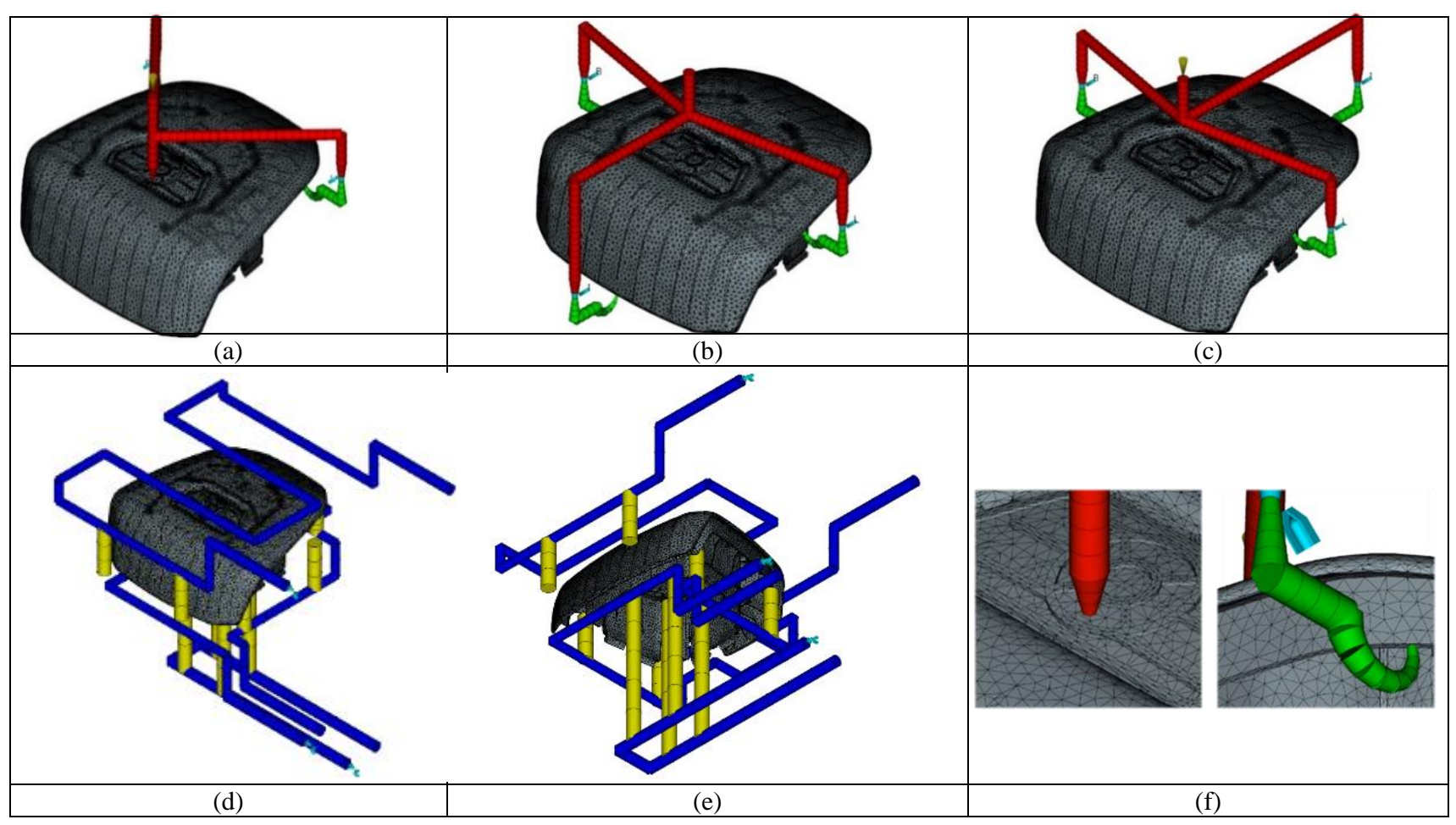

Figure 3. Analysis model of horn cover : (a) type 1 (b) type 2 (c) type 3 (d) cooling channel of the fixed half (e) cooling line for the moving half (f) hot gate and valve gate

The condition before the improvement of injection molding parameters is recorded in Table 3 . Except for the open-close time of the valve gate, the three models adopt the same injection molding parameters given in Table 3. Table 4 shows the valve gate open-close time applied to the three analysis models.

Autodesk Moldflow Insight 2021 was used for injection molding numerical analysis [26-29]. Tetrahedral elements were used for the analysis modeling: the total number of elements is approximately $1,162,970$.

Table 3. Original injection molding condition before the optimization

\begin{tabular}{|c|c|c|}
\hline Injection molding parameters & Unit & Values \\
\hline Injection time & $\mathrm{sec}$ & 2.8 \\
\hline Holding pressure & $\mathrm{MPa}$ & 35 \\
\hline Holding time & $\mathrm{sec}$ & 6 \\
\hline Cooling time & $\mathrm{sec}$ & 22 \\
\hline Mold temperature & ${ }^{\circ} \mathrm{C}$ & 40 \\
\hline Melt temperature & ${ }^{\circ} \mathrm{C}$ & 200 \\
\hline Fixed plates coolant temp. & ${ }^{\circ} \mathrm{C}$ & 25 \\
\hline Moving plates coolant temp. & ${ }^{\circ} \mathrm{C}$ & 25 \\
\hline
\end{tabular}

Table 4. Valve gate open-close time

\begin{tabular}{|c|c|c|c|c|}
\hline & Unit & Type 1 & Type 2 & Type 3 \\
\hline Open time & $\mathrm{s}$ & 2.5 & 1.3 & 1.7 \\
\hline Close time & $\mathrm{s}$ & 9.0 & 9.0 & 9.0 \\
\hline
\end{tabular}




\section{Results and discussions}

\subsection{Comparison of analysis results}

Table 5 shows the main results of the analysis. The order of magnitude of the maximum injection pressure is type 2-3-1. The results show that type 1 produces a maximum injection pressure of approximately $13 \mathrm{MPa}$ lower than the remaining types 2 and 3. This result is believed to be caused by the relatively low flow resistance due to the short flow distance compared to the other types, as the main hot gate of type 1 is located in the center of the mold. Clamping force is required to clamp the mold to prevent it from opening during inject of melt resin. Therefore, the clamping force is proportional to the injection pressure. For this reason, the order of magnitude of the clamping force is the same as that of the injection pressure. Figure 4 shows the distribution of the deflections. Due to the characteristic of the molding shape, the maximum deflections of all three types occur at both ends of the molding. It can be seen that the size of the maximum deflection is in the order of type 2-1-3. Figure 5 shows the profiles of filling time. The filling times are almost the same, with type 1 showing a value $3.032 \mathrm{~s}$, type 2 showing $3.023 \mathrm{~s}$, and type 3 showing $3.035 \mathrm{~s}$; however, the flow pattern of type 1 is the most uniform at 2.274 s. If mold is filled unevenly, such as when using types 2 and 3, the filled part will cool down first, which will increase injection pressure. The increased injection pressure acts as a residual stress on the mold, causing deflection. In addition, a weldline may occur at the last point that resin meets. Figure 6 shows that unlike type 1, type 2 and type 3 have a weldline in the area that melt resin unevenly filled.

Table 5. Analysis results for three different types

\begin{tabular}{|c|c|c|c|c|}
\hline & Unit & Type 1 & Type 2 & Type 3 \\
\hline Max. injection pressure & $\mathrm{MPa}$ & 43.89 & 57.26 & 56.34 \\
\hline Clamping force & tonne & 92.56 & 103.0 & 96.99 \\
\hline Max. deflection & $\mathrm{mm}$ & 0.4029 & 0.4344 & 0.3601 \\
\hline Fill time & $\mathrm{s}$ & 3.032 & 3.023 & 3.035 \\
\hline
\end{tabular}

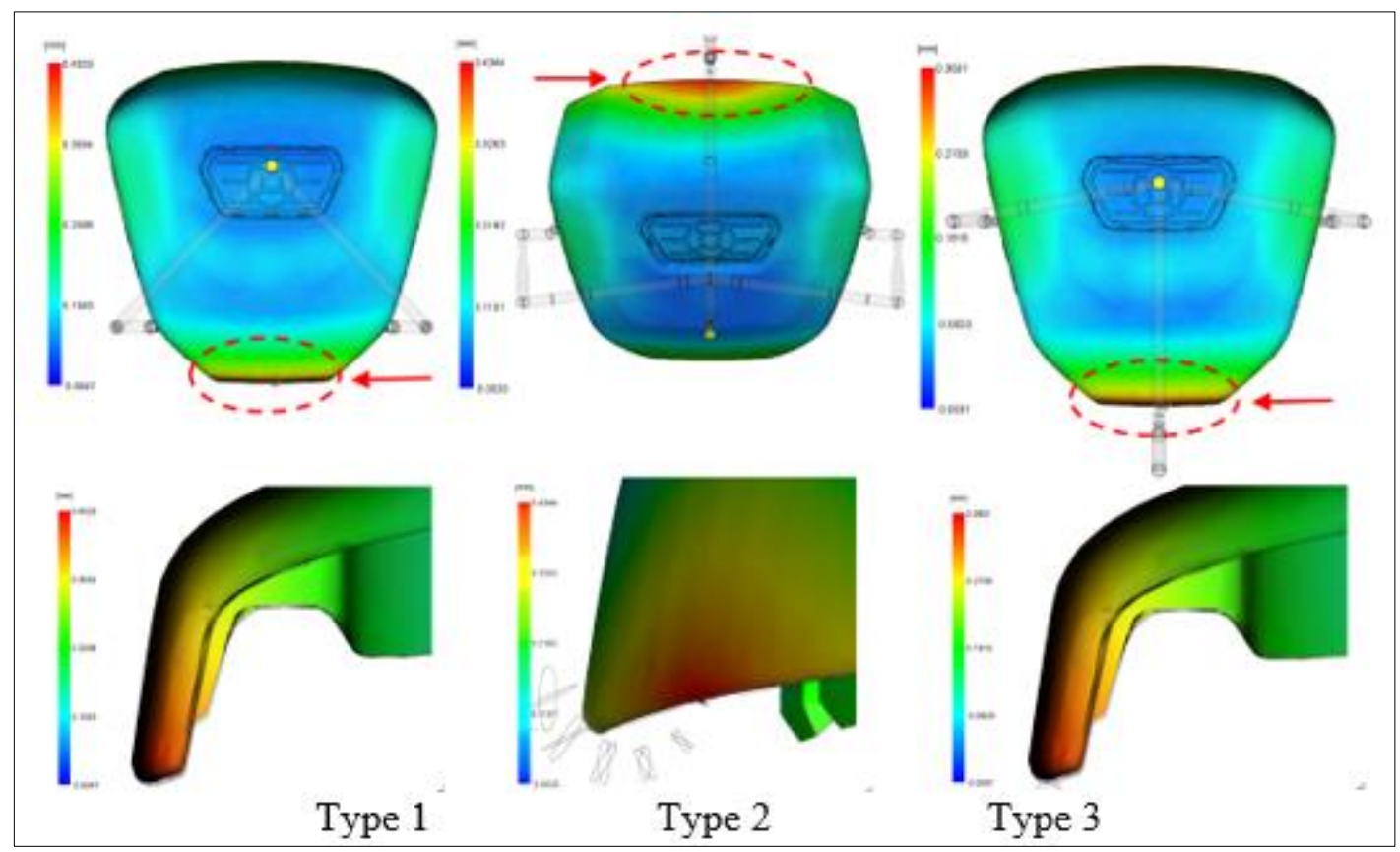

Figure 4. Distribution of deflection 


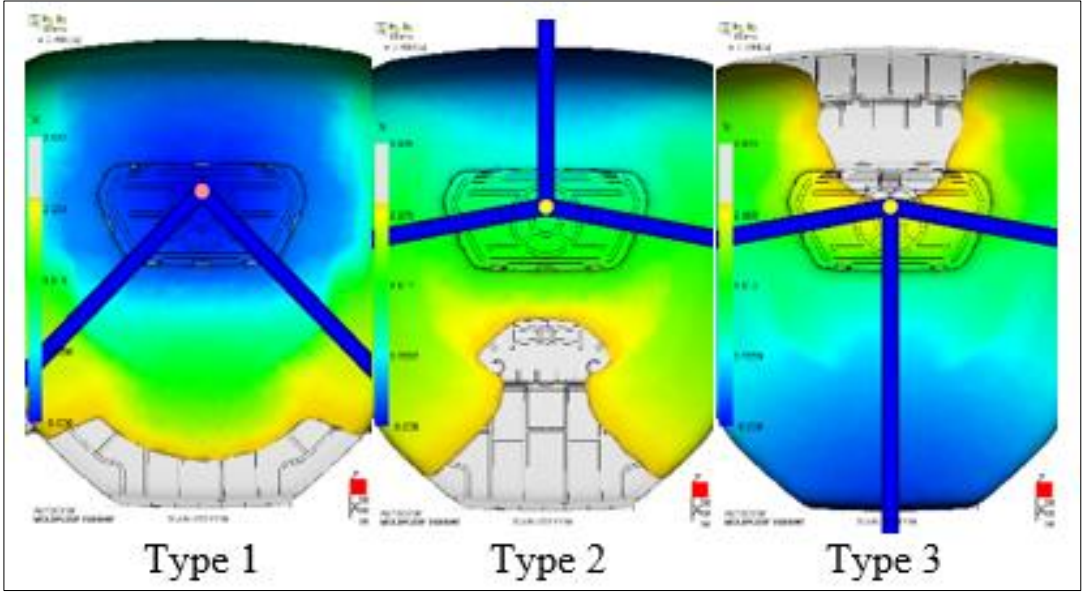

Figure 5. Profiles of filling time

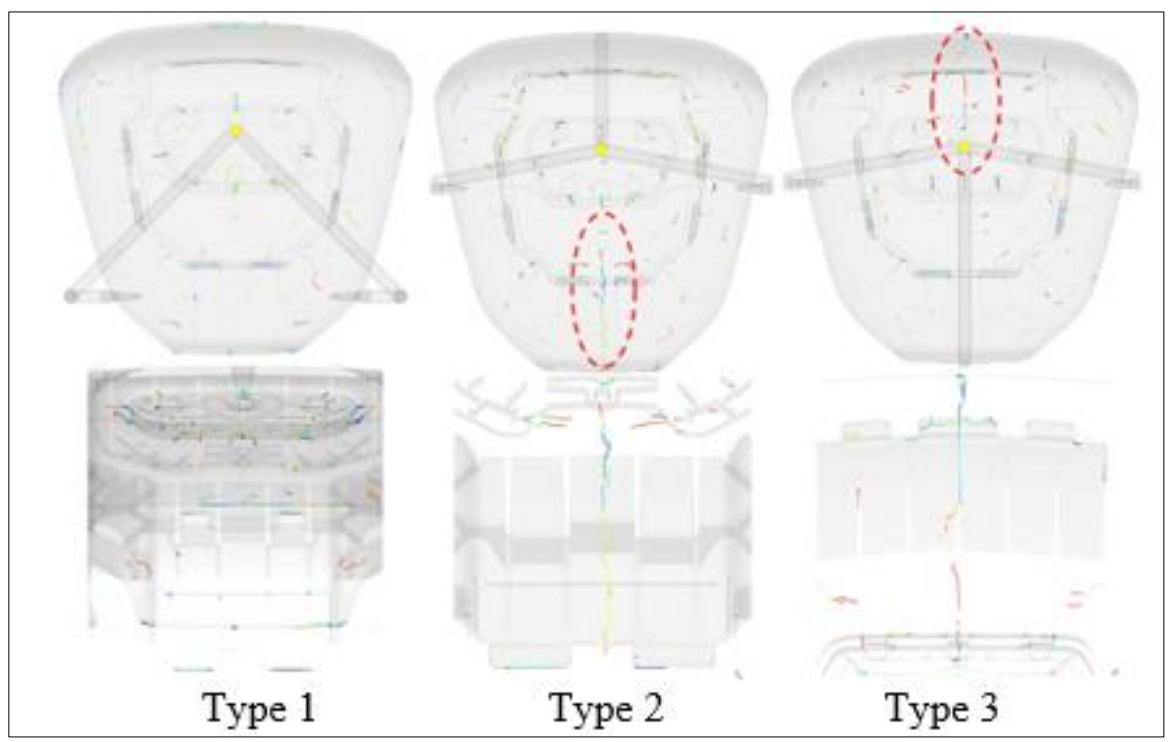

Figure 6. Occurrence of weldline

\subsection{Selection of mold type}

Considering the previous analysis results, type 1 with a hot gate in the center was selected as the final model. First, because the injection pressure and clamping force of type 1 were the lowest, it is believed that the burden of the mold and injection molding machine will be the least. Second, the horn cover is a component attached to the steering wheel of an automobile and is directly visible to the user. Therefore, if a weldline occurs outside the molded product, it is not good in appearance. It is also a part that receives a lot of finger pressure. Therefore, it is considered that types 2 and 3 , which have weldlines that can reduce the strength, are not suitable. Third, type 1 shows a uniform flow of resin compared to other types. Therefore, it is believed that gas ventilation will be smooth at the end of the molding process. However, type 1 has a gate connected to the center outside of the molding. Usually, if a gate is located outside of molding, it leaves a gate mark, which is not suitable for the appearance. However, in the case of this cover molding, the company logo molding will be assembled in the central gate location, so there is no apparent problem. In addition, type 3 has the smallest deflection. However, the deflection amount is a fine difference of $0.04 \mathrm{~mm}$ compared to type 1 . For this reason, type 1 was selected as the final mold model.

\subsection{Taguchi method for optimal injection molding parameters}

A design of experiment was planned to obtain the optimal injection molding parameters before 
producing injection molds with the optimal gate location results obtained earlier. In this study, the Taguchi method was used for the design of the experiment. The Taguchi method is an optimization technique that has been proven to be effective in the past and has been used so far for low cost and fast delivery not only by companies related to molds but also by companies in various fields.

The main parameters to be applied to the Taguchi method were the holding pressure, melt temperature, coolant temperature, and cooling time, which are thought to impact the deflection of the molding significantly. All other molding parameters were applied the same as the existing molding parameters before the experiment was conducted. Table 6 is a representation of the significant parameters and levels applied to the Taguchi method. Each parameter was organized into five levels.

Table 6. Parameters and levels

\begin{tabular}{|c|c|c|c|c|c|}
\hline \multirow{2}{*}{ Parameters } & \multicolumn{5}{|c|}{ Levels } \\
\cline { 2 - 6 } & $\mathbf{1}$ & $\mathbf{2}$ & $\mathbf{3}$ & $\mathbf{4}$ & $\mathbf{5}$ \\
\hline A. Holding pressure $(\mathbf{M P a})$ & 31 & 33 & 35 & 37 & 39 \\
\hline B. Melt temperature $\left({ }^{\circ} \mathbf{C}\right)$ & 170 & 185 & 200 & 215 & 230 \\
\hline C. Coolant temp. $\left({ }^{\circ} \mathbf{C}\right)$ & 21 & 23 & 25 & 27 & 29 \\
\hline D. Cooling time (s) & 18 & 20 & 22 & 24 & 26 \\
\hline
\end{tabular}

A total of 625 experiments must be conducted to include all four parameters and five levels per parameter. However, using the Taguchi method, it is possible to identify parameters that affect injection molding deflection even after 25 experiments. In addition, replacing 25 experiments designed with the Taguchi method with injection molding analysis can save significant time and money for actual injection molding experiments. In other words, the Taguchi method is an optimal experimental method that can be effectively applied to injection molding analysis.

Table 7 summarizes the 25 experiments in an orthogonal array of L25. Here, No. 1 in the orthogonal array means an experiment combining $31 \mathrm{MPa}$ of holding pressure, $170^{\circ} \mathrm{C}$ of melt temperature, $21^{\circ} \mathrm{C}$ of coolant temperature, and $18 \mathrm{~s}$ of cooling time.

Table 7. $\mathrm{L}^{25}$ Orthogonal array

\begin{tabular}{|c|c|c|c|c|}
\hline No. & $\boldsymbol{A}$ & $\boldsymbol{B}$ & $C$ & $D$ \\
\hline 1 & 1 & 1 & 1 & 1 \\
\hline 2 & 1 & 2 & 2 & 2 \\
\hline 3 & 1 & 3 & 3 & 3 \\
\hline 4 & 1 & 4 & 4 & 4 \\
\hline 5 & 1 & 5 & 5 & 5 \\
\hline 6 & 2 & 1 & 2 & 3 \\
\hline 7 & 2 & 2 & 3 & 4 \\
\hline 8 & 2 & 3 & 4 & 5 \\
\hline 9 & 2 & 4 & 5 & 1 \\
\hline 10 & 2 & 5 & 1 & 2 \\
\hline 11 & 3 & 1 & 3 & 5 \\
\hline 12 & 3 & 2 & 4 & 1 \\
\hline 13 & 3 & 3 & 5 & 2 \\
\hline 14 & 3 & 4 & 1 & 3 \\
\hline 15 & 3 & 5 & 2 & 4 \\
\hline 16 & 4 & 1 & 4 & 2 \\
\hline 17 & 4 & 2 & 5 & 3 \\
\hline 18 & 4 & 3 & 1 & 4 \\
\hline
\end{tabular}




\begin{tabular}{|l|l|l|l|l|}
\hline $\mathbf{1 9}$ & 4 & 4 & 2 & 5 \\
\hline $\mathbf{2 0}$ & 4 & 5 & 3 & 1 \\
\hline $\mathbf{2 1}$ & 5 & 1 & 5 & 4 \\
\hline $\mathbf{2 2}$ & 5 & 2 & 1 & 5 \\
\hline $\mathbf{2 3}$ & 5 & 3 & 2 & 1 \\
\hline $\mathbf{2 4}$ & 5 & 4 & 3 & 2 \\
\hline $\mathbf{2 5}$ & 5 & 5 & 4 & 3 \\
\hline
\end{tabular}

The injection molding experiments were carried out based on the orthogonal array table (Table 7). The results of each experimental case were analyzed by calculating the $\mathrm{S} / \mathrm{N}$ ratio (signal-to-noise ratio). The smaller the deflection of injection molding, the better. Therefore, the process corresponds to the SB (smaller the better) of the Taguchi method. The formula for obtaining the S/N ratio of the $\mathrm{SB}$ is given by

$$
S N=-10 \log \left[\frac{1}{n} \Sigma y_{i j}^{2}\right]
$$

with the unit of $\mathrm{dB}$ [30] and where $n$ is the number of experiments by level for each major parameter and $y_{i j}$ is the characteristic values for each experiment.

Table 8 shows the maximum deflection value and $\mathrm{S} / \mathrm{N}$ ratio of each experiment. Since the deflection amount is characterized by the "SB", the smaller the deflection amount, the greater the $\mathrm{S} / \mathrm{N}$ ratio value. For reference, the bigger the $\mathrm{S} / \mathrm{N}$ ratio value, the better. $\mathrm{S} / \mathrm{N}$ ratio calculations were made using Minitab 2018, a statistical processing program.

Table 8. The values of deflection and $\mathrm{S} / \mathrm{N}$ ratio

\begin{tabular}{|c|c|c|}
\hline No. & Deflections & S/N ratio(dB) \\
\hline $\mathbf{1}$ & 0.2600 & 11.7005 \\
\hline $\mathbf{2}$ & 0.2598 & 11.7072 \\
\hline $\mathbf{3}$ & 0.3045 & 10.3283 \\
\hline $\mathbf{4}$ & 0.3225 & 9.82941 \\
\hline $\mathbf{5}$ & 0.3636 & 8.78752 \\
\hline $\mathbf{6}$ & 0.2655 & 11.5187 \\
\hline $\mathbf{7}$ & 0.2943 & 10.6242 \\
\hline $\mathbf{8}$ & 0.3561 & 8.96856 \\
\hline $\mathbf{9}$ & 0.3396 & 9.38065 \\
\hline $\mathbf{1 0}$ & 0.3566 & 8.95637 \\
\hline $\mathbf{1 1}$ & 0.2881 & 10.8091 \\
\hline $\mathbf{1 2}$ & 0.3467 & 9.20092 \\
\hline $\mathbf{1 3}$ & 0.3960 & 8.04610 \\
\hline $\mathbf{1 4}$ & 0.4026 & 7.90252 \\
\hline $\mathbf{1 5}$ & 0.4005 & 7.94795 \\
\hline $\mathbf{1 6}$ & 0.3278 & 9.68782 \\
\hline $\mathbf{1 7}$ & 0.3955 & 8.05707 \\
\hline $\mathbf{1 8}$ & 0.4400 & 7.13095 \\
\hline $\mathbf{1 9}$ & 0.4554 & 6.83214 \\
\hline $\mathbf{2 0}$ & 0.4134 & 7.67259 \\
\hline $\mathbf{2 1}$ & 0.3616 & 8.83543 \\
\hline $\mathbf{2 2}$ & 0.4216 & 7.50199 \\
\hline $\mathbf{2 3}$ & 0.4791 & 6.39148 \\
\hline $\mathbf{2 4}$ & 0.4688 & 6.58025 \\
\hline $\mathbf{2 5}$ & 0.4617 & 6.71280 \\
\hline & & \\
\hline
\end{tabular}

Figure 7 shows the variation of the calculated $\mathrm{S} / \mathrm{N}$ ratio. Combining the points with the highest $\mathrm{S} / \mathrm{N}$ ratio in each major parameter graph yields the optimum molding condition, in which the amount of deflection of the molding is minimal. Therefore, it can be seen that the optimum molding 
parameters are holding pressure of $31 \mathrm{MPa}$, melt temperature of $170^{\circ} \mathrm{C}$, coolant temperature of $25^{\circ} \mathrm{C}$, and cooling time of $20 \mathrm{~s}$.

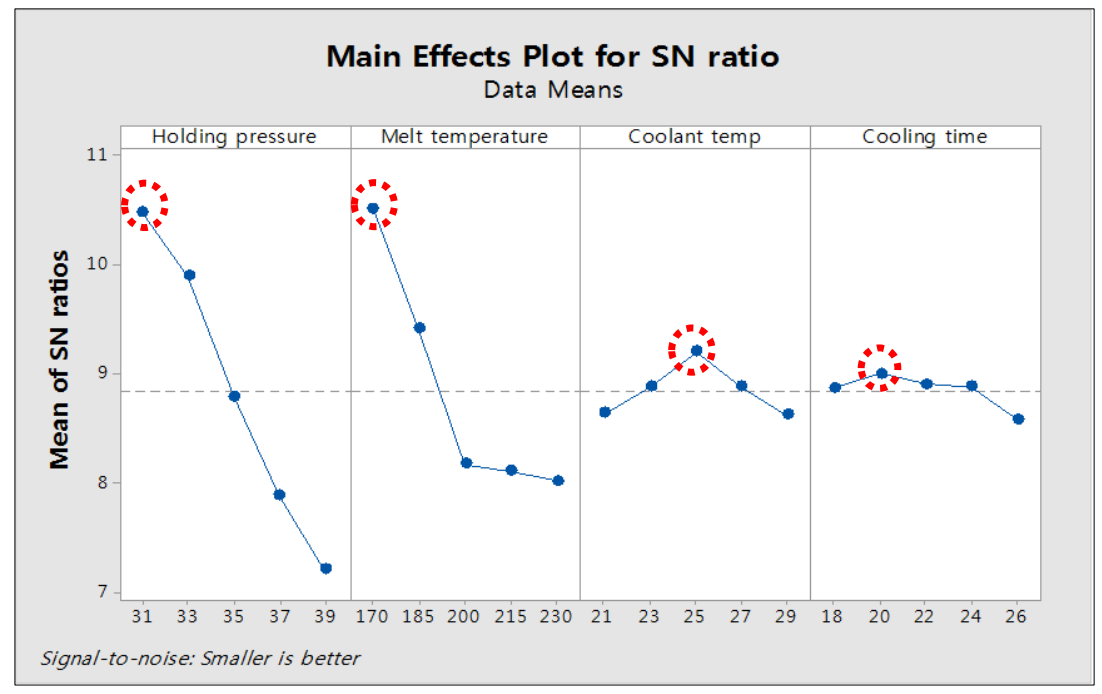

Figure 7. Main effects plot of $\mathrm{S} / \mathrm{N}$ ratios

Table 9 presents the $\mathrm{S} / \mathrm{N}$ ratios for each level of four parameters, where the delta value indicates the differences between the maximum and minimum $\mathrm{S} / \mathrm{N}$ ratios for each parameter. Meanwhile, the rank is graded in the magnitude of delta value because a large delta means a larger change in the $\mathrm{S} / \mathrm{N}$ ratio. In other words, a parameter having a higher rank means that the vibration of $\mathrm{S} / \mathrm{N}$ ratios to that level is larger, giving rise to more effect on the characteristic.

It can be seen that the higher the delta value is, the greater the influence on the deflection amount of the molding. Therefore, it can be seen that the order of molding parameters that have a great influence on the deflection of the molding is holding pressure, melt temperature, cooling temperature, and cooling time. And, among these molding parameters, the main parameter that is effective for deflection of the molding is the S/N ratio value. Also, ANOVA was performed to grasp the relative effects better, with results shown in Table 10. When the significance level was set at 5\% in the variance analysis, the significant parameters were holding pressure (A) and melt temperature (B). If the P-value is lower than 0.05 , it can be judged as an essential parameter. It was confirmed that the holding pressure (A) and melt temperature (B) are the molding parameters that significantly influence the molding deflection amount.

Table 9. Results of $\mathrm{S} / \mathrm{N}$ ratio for each parameter

\begin{tabular}{|c|c|c|c|c|}
\hline \multirow{2}{*}{ Levels } & \multicolumn{3}{|c|}{ S/N ratio } \\
\cline { 2 - 5 } & $\mathbf{A}$ & $\mathbf{B}$ & $\mathbf{C}$ & $\mathbf{D}$ \\
\hline $\mathbf{1}$ & 10.471 & 10.510 & 8.638 & 8.869 \\
\hline $\mathbf{2}$ & 9.890 & 9.418 & 8.879 & 8.996 \\
\hline $\mathbf{3}$ & 9.405 & 8.173 & 9.203 & 8.904 \\
\hline $\mathbf{4}$ & 7.876 & 8.729 & 8.880 & 8.874 \\
\hline $\mathbf{5}$ & 7.204 & 8.015 & 8.621 & 8.580 \\
\hline Delta & 3.266 & 2.495 & 0.582 & 0.416 \\
\hline Rank & 1 & 2 & 3 & 4 \\
\hline
\end{tabular}

Table 10. Analysis of variance of $\mathrm{S} / \mathrm{N}$ ratio

\begin{tabular}{|c|c|c|c|c|c|}
\hline Parameters & DF & Adj SS & Adj MS & F-value & P-value \\
\hline A & 4 & 0.064382 & 0.016096 & 51.27 & 0.000 \\
\hline B & 4 & 0.038653 & 0.009663 & 30.78 & 0.000 \\
\hline C & 4 & 0.001587 & 0.000397 & 1.26 & 0.359 \\
\hline D & 4 & 0.000690 & 0.000172 & 0.55 & 0.705 \\
\hline e & 8 & 0.002512 & 0.000314 & - & - \\
\hline Total & 24 & 0.107824 & & - & - \\
\hline
\end{tabular}


The optimal molding condition, which combines the maximum $\mathrm{S} / \mathrm{N}$ ratio values for each parameter, is applied to the modeling of type 1 to perform injection molding analysis and results are compared with maximum deflection result of type 1 before molding condition optimization. Figure 8 shows the results of deflection obtained by applying the optimal molding condition. The maximum deflection was approximately $0.2648 \mathrm{~mm}$. This result decreases about $34.3 \%$ compared to the maximum deflection of the type 1 model before the molding condition optimization.

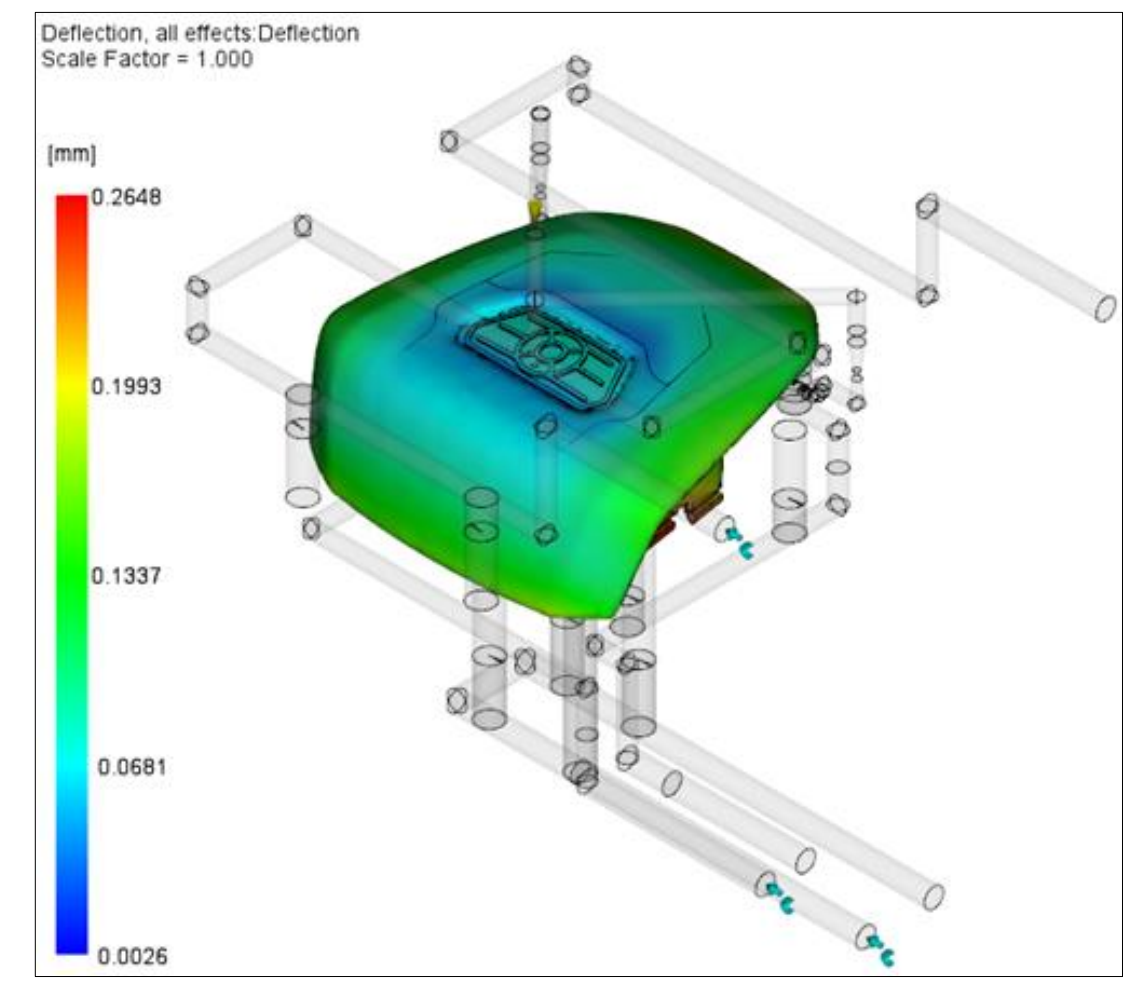

Figure 8. Deflection profile when the optimal condition was applied

\subsection{Horn cover molding evaluation}

The results of the injection molding numerical analysis based on the Taguchi method were analyzed, and the selected injection mold type 1 was actually manufactured. The size of the mold is $590 \mathrm{~mm}$ (horizontal) $\times 620 \mathrm{~mm}$ (vertical) $\times 720 \mathrm{~mm}$ (height); mold consisted of one cavity, and a hot runner was inserted into the mold for sequential opening and closing of valve gates. The injection molding machine used in injection molding was LGH300ton horizontal injection machine.

Dimensional precision of molded horn covers was measured to verify optimal molding parameters and the validity of manufactured molds. The amount of deflection in the critical positions of the horn cover was measured with dimensional precision. Deflection measurement of the horn cover was carried out using a precision 3D scanner. Figure 9 provides a picture of deflection measuring of a horn cover molded with a 3D scanner. The 3D scanner is Breckmann's SmartSCAN ${ }^{3 \mathrm{D}}$, and the measurement accuracy is $12 \mu \mathrm{m}$. 


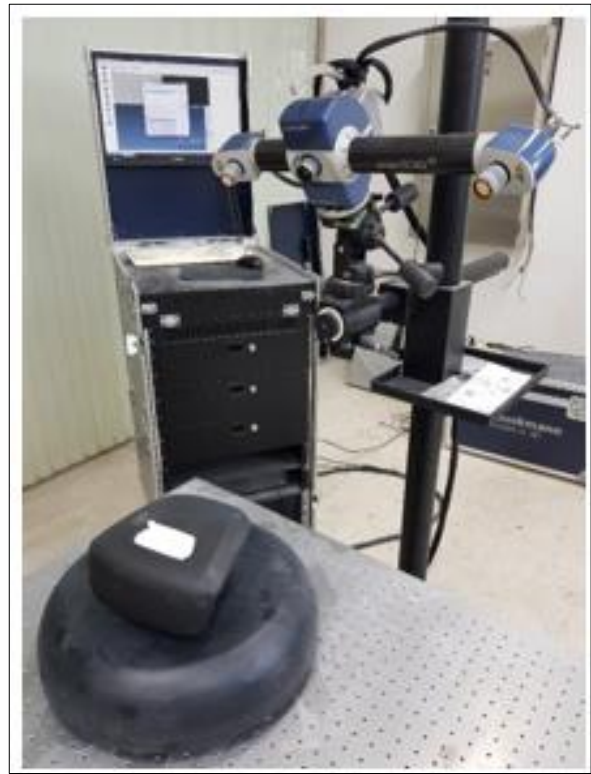

Figure 9.3D scanning for checking dimensional accuracy

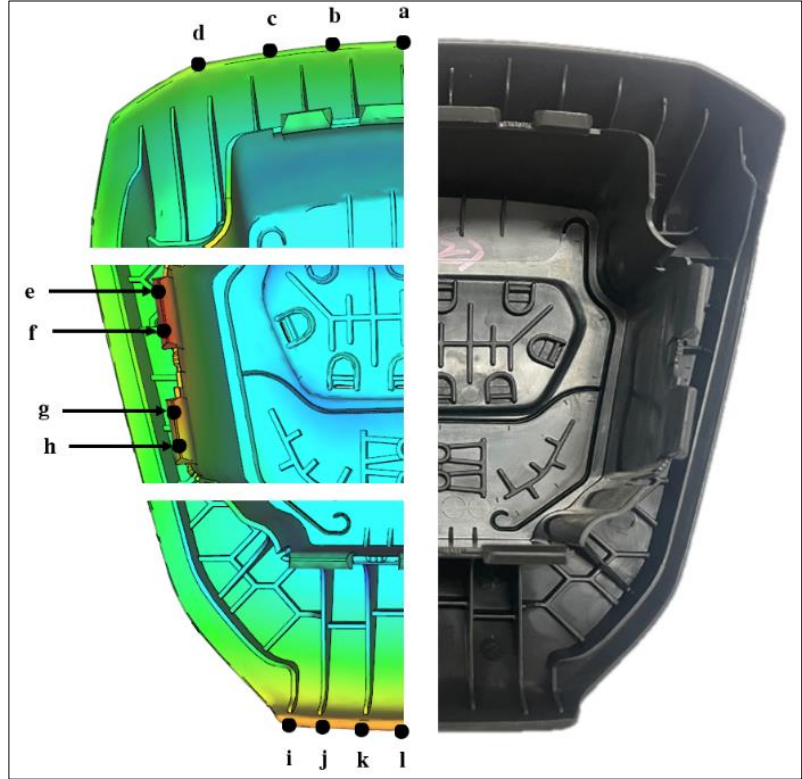

Figure 10. Deflection amount measurement point

Figure 10 shows the measurement points selected to compare the deflection amount. The measurement points of the deflection amount of the molding were determined in three places-the upper and lower of the horn cover and the snap fit inside. Table 11 provides molding deflection amount before optimization of molding parameters, molding deflection amount from analysis of molding parameters, and the actual molding deflection amount by measurement points. The molding deflection amount in the results of plastic analysis using optimal molding parameters was the smallest. The actual molding deflection amount showed a slightly higher value than in the results of plastic analysis using the optimal molding parameters. These results are considered to be different due to simplification and many assumptions applied to the analysis model and formula for smooth progression of injection molding analysis.

Table 11. Deflection amount by measurement location

\begin{tabular}{|c|c|c|c|c|}
\hline \multicolumn{2}{|c|}{ Measurement point } & Before optimization & Optimized analysis & Actual molding \\
\hline \multirow{4}{*}{ Upper } & $\mathbf{a}$ & 0.3005 & 0.1562 & 0.2154 \\
\hline & $\mathbf{b}$ & 0.2965 & 0.1563 & 0.2299 \\
\hline & c & 0.2758 & 0.1541 & 0.2356 \\
\hline & d & 0.2743 & 0.1713 & 0.2554 \\
\hline \multirow{4}{*}{ Snap fit } & e & 0.3161 & 0.2648 & 0.2975 \\
\hline & f & 0.3095 & 0.2491 & 0.2885 \\
\hline & g & 0.2561 & 0.2284 & 0.2352 \\
\hline & h & 0.2132 & 0.2026 & 0.2238 \\
\hline \multirow{4}{*}{ Lower } & i & 0.3891 & 0.2333 & 0.3189 \\
\hline & $\mathbf{j}$ & 0.3993 & 0.2369 & 0.3222 \\
\hline & $\mathbf{k}$ & 0.3960 & 0.2331 & 0.3289 \\
\hline & 1 & 0.4004 & 0.2353 & 0.3162 \\
\hline
\end{tabular}

Figure 11 shows a graph comparing the deflection amount in the upper area. Compared to the deflection amount before optimization, the deflection amount of the injection molding analysis after optimization decreased by about $43.5 \%$ or more. However, compared to the deflection amount of the optimized molding analysis, it was found that the actual molding deflection amount increased by about $43 \%$. Figure 12 provides a graph comparing the deflection amounts of the snap fit. The range of change was narrower than that of the deflection amount in the previous upper area. The tendency is similar to the upper area. Compared to the deflection amount before optimization, the deflection amount of the molding analysis after optimization decreased by about $15.5 \%$ or more. However, compared to the 
deflection amount of the optimized molding analysis, it was found that the actual molding deflection amount increased by about $11.1 \%$. Figure 13 provides a graph comparing the deflection amounts at the lower area. The deflection amount at the lower point is larger than the deflection amount in the upper and snap fit area. The range of change was narrower than that of the deflection amount in the previous upper area. Compared to the deflection amount before optimization, the deflection amount in the molding analysis after optimization decreased by about $40.7 \%$ or more. However, compared to the deflection amount of the optimized molding analysis, it was found that the actual molding deflection amount increased by about $37.0 \%$.

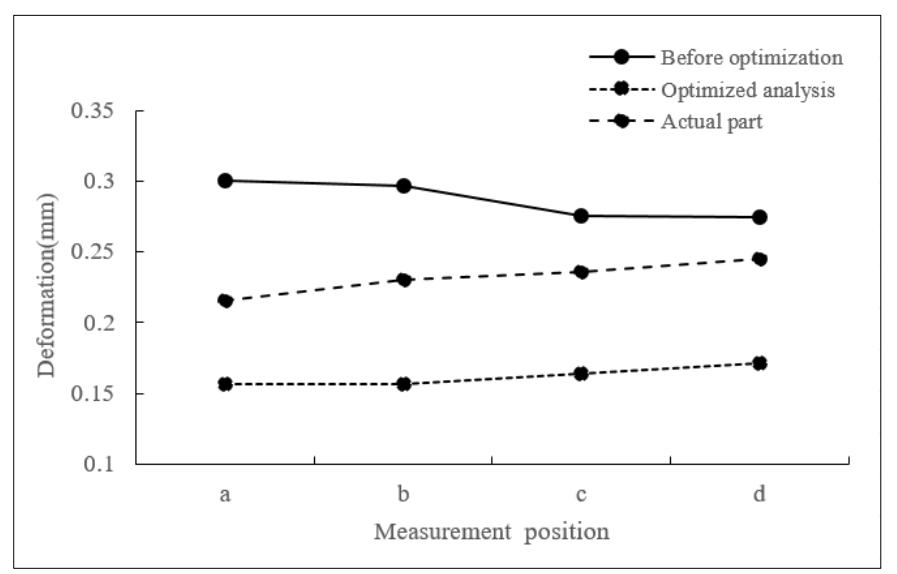

Figure 11. Comparison of deflection amount at the upper

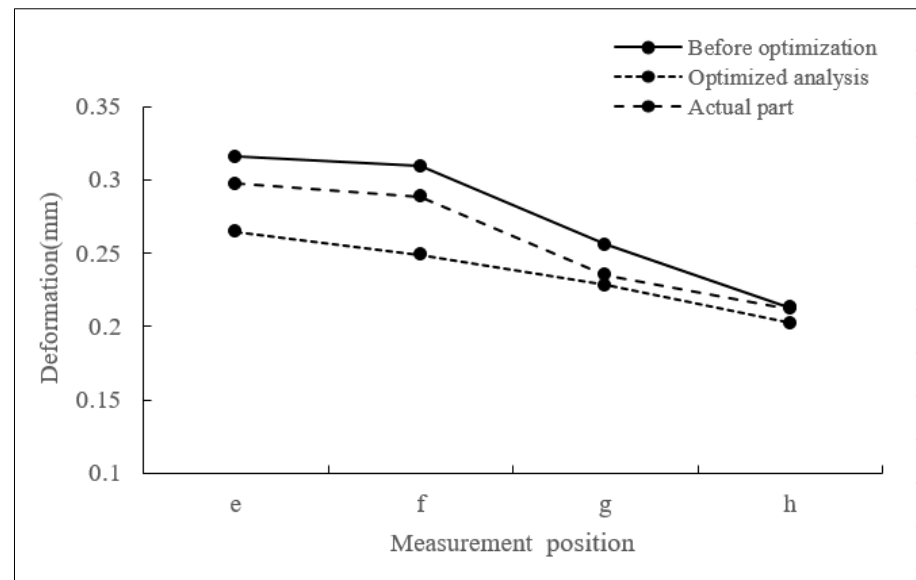

Figure 12. Comparison of deflection amount at the snap fit

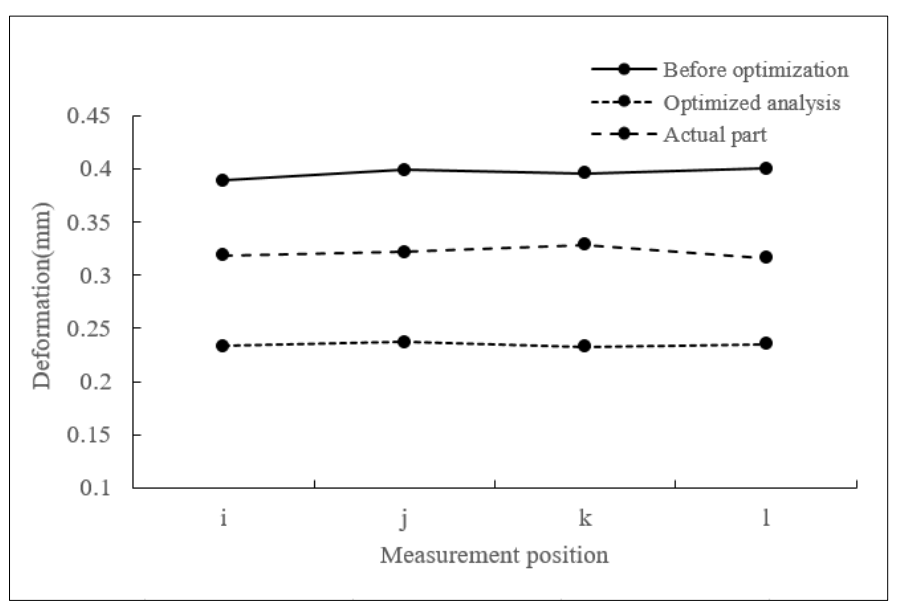

Figure 13. Comparison of deflection amount at the lower 


\subsection{Revision of injection mold}

The deflection amount, identified through a 3D scanning operation, was used as data for revising the mold. The mold revision is used to modify the mold in a direction opposite to the deflection and equal to the measured deflection amount. Figure 14 shows the revised mold.

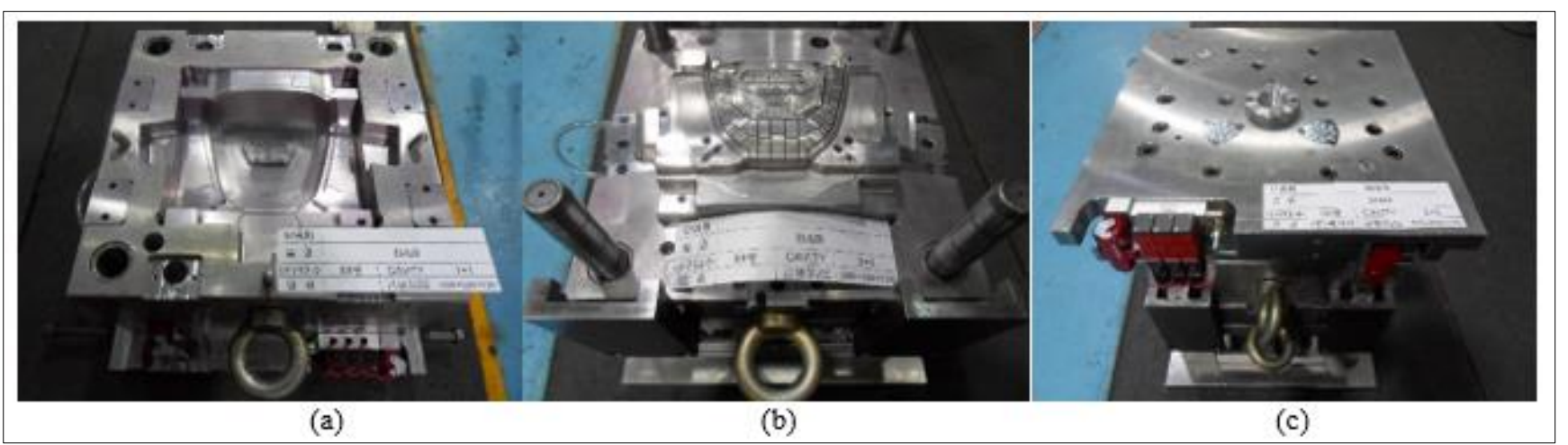

Figure 14. Horn cover mold: (a) fixed half (b) moving half (c) assembled mold

Figure 15 shows the horn cover molding using the revised mold. Center gate traces can be found at the front center of the horn cover. In addition, it can be seen that there are no cosmetic defects such as weldline and sink mark. The molded horn cover was measured and found to satisfy most of the required dimensions. As a result, it was assembled on an actual vehicle, as shown in Figure 16.

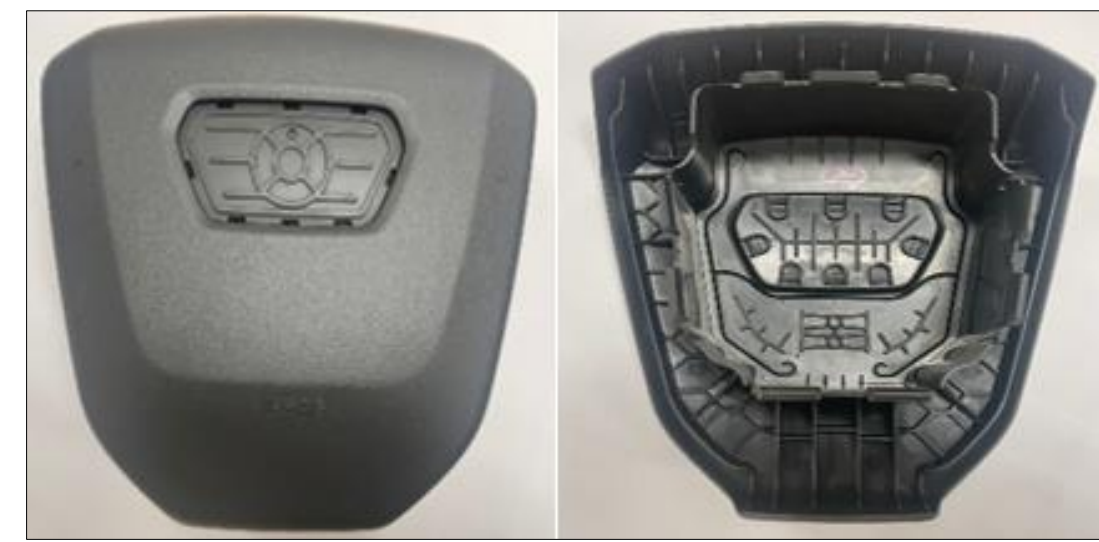

Figure 15. Final molded horn cover: (a) front (b) back

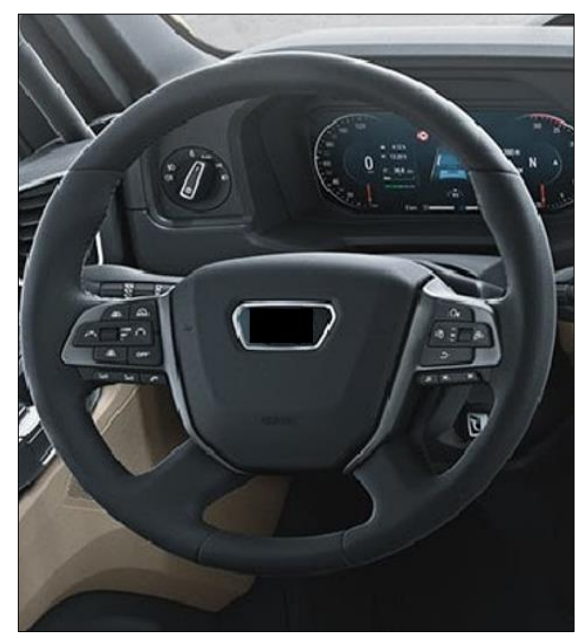

Figure 16. Horn cover mounted on an automobile 


\section{Conclusions}

In this study, an injection mold for molding a plastic horn cover assembled on an automobile steering wheel was developed, and an injection molding optimization study was conducted for optimal injection molding of a horn cover. The conclusions obtained during the study are as follows.

Based on the shape of the plastic horn cover, three injection mold types with different resin flow systems were designed. Among the three designed injection molds, one mold type that satisfies the surface quality of a molded horn cover molded was selected. Whether or not the surface quality of the molding was satisfied was analyzed by performing injection molding analysis, and the results were analyzed and confirmed. A design of experiment (DOE) was constructed to obtain optimal injection molding parameters for the selected mold. Taguchi method was used according to the DOE, and optimal injection molding parameters were obtained through ANOVA.

The selected injection mold type was actually manufactured, and the horn cover was molded by applying the optimal injection molding parameters obtained by the Taguchi method. A 3D scanner, which is mainly used in benchmarking, was used to confirm the dimensional accuracy of the molded horn cover. The deflection amount measured by the 3D scanner and the results of numerical analysis by applying optimal injection molding parameters were compared. As a result, it was found that the actual deflection amount of the horn cover is larger than the deflection amount of the numerical analysis result. The mold manufactured based on the deflection amount measured by 3D scan was revised further to reduce the deflection amount of the actual horn cover. The horn cover manufactured using the revised mold satisfies all product requirements and can be used as a product assembled on an actual automobile wheel.

\section{References}

1. HAN, S. R., PARK, J. I., CHO, J. R., Development of plastic passenger air bag (PAB) housing for replacing the steel PAB housing and reducing the automobile weight, Journal of the Brazilian Society of Mechanical Sciences and Engineering, 40(4), 2018, 1-10.

https://doi.org/10.1007/s40430-018-1040-9

2. OSSWALD, T. A., Polymer processing fundamentals, 1998.

3. PÖTSCH, G., MICHAELI, M., Injection molding an introduction, 1995.

4. HAN, S. R., CHO, J. R., BEAK, S. K., HONG, J. A., LEE, Y. S., Numerical and experimental studies on injection compression molding process for thick plastic gas valve stem, International Journal of Advanced Manufacturing Technology, 89(1-4), 2017, 651-660.

https://doi.org/10.1007/s00170-016-9139-6

5. HUAMIN, Z., Computer modeling for injection molding: Simulation, Optimization, and Control, John Wiley \& Sons, New Yersey, 2013.

6. SZABÓ, F., SUPLICZ, A., KOVÁCS, J. G., Development of injection molding simulation algorithms that take into account segregation, Powder Technology, 389, 2021, 368-375.

https://doi.org/10.1016/j.powtec.2021.05.053

7.CHEN, J. Y., HUNG, P. H., HUANG, M. S., Determination of process parameters based on cavity pressure characteristics to enhance quality uniformity in injection molding, International Journal of Heat and Mass Transfer, 180, 2021, 121788.

https://doi.org/10.1016/j.ijheatmasstransfer.2021.121788

8.LI, K., YAN, S., ZHONG, Y., PAN, W., ZHAO, G., Multi-objective optimization of the fiberreinforced composite injection molding process using Taguchi method, RSM, and NSGA-II, Simul. Model. Pract. Theory, 91, 2019, 69-82, https://doi.org/10.1016/j.simpat.2018.09.003

9.XAVIER, S. S., ALEX, E. Z., MARCELO, H. A., Processing of ultra-high molecular weight polyethylene/graphite composites by ultrasonic injection moulding: Taguchi optimization, Ultrasonics Sonochemistry, 44, 2018, 350-358. https://doi.org/10.1016/j.ultsonch.2018.02.042 
10.MOAYYEDIAN, M., ABHARY, K., MARIAN, R., Optimization of injection molding process based on fuzzy quality evaluation and Taguchi experimental design, CIRP Journal of Manufacturing Science and Technology, 21, 2018, 150-160, https://doi.org/10.1016/j.cirpj.2017.12.001

11.SREEDHARAN, J., JEEVANANTHAM, A., Optimization of Injection molding process to minimize weld-line and sink-mark defects using Taguchi based grey relational analysis, Materials Today: Proceedings, 5, 2020, 12615-12622, https://doi.org/10.1016/j.matpr.2018.02.244

12.BENSINGH, R.J., MACHAVARAM, R., BOOPATHY, S.R., JEBARAJ, C., Injection molding process optimization of a bi-aspheric lens using hybrid artificial neural networks (ANNs) and particle swarm optimization (PSO), Measurement, 134, 2019, 359-374.

https://doi.org/10.1016/j.measurement.2018.10.066

13.KUMAR, B.P., VENKATARAMAIAH, P., GANESH, J., Optimization of process parameters in injection moulding of a polymer composite product by using Gra., Materials Today: Proceedings, 18, 2019, 4637-4647, https://doi.org/10.1016/j.matpr.2019.07.448

14.SHEN, C., WANG, L., LI, Q., Optimization of injection molding process parameters using combination of artificial neural network and genetic algorithm method, Journal of Materials Processing Technology, 183, 2007, 412-418, https://doi.org/10.1016/j.jmatprotec.2006.10.036

15.XIN, L., SHARIF, S., SAAD, R.M., Gas-assisted injection molding: case study on process of CDrom tray manufacturing, Procedia Manufacturing, 2, 2015, 538-542.

https://doi.org/10.1016/j.promfg.2015.07.093

16.OTHMAN, M.H., HASAN, S., KHAMIS, S.Z., IBRAHIM, M., AMIN, S.Y., Optimisation of injection moulding parameter towards shrinkage and warpage for polypropylene-nanoclay-gigantochloa scortechinii nanocomposites, Procedia Engineering, 184, 2017, 673-680.

https://doi.org/10.1016/j.proeng.2017.04.137

17.JEONG, S. J., MOON, S. J., JEOUNG, S. K., LEE, P. C., \& MOON, J. H., Optimization of process parameters of die slide injection by using Taguchi method, Korean Chemical Engineering Research, 50 (2), 2012, 264-269, https://doi.org/10.9713/kcer.2012.50.2.264

18.SINGH, G., PRADHAN, M.K., VERMA, A., Multi response optimization of injection moulding process parameters to reduce cycle time and warpage, Materials Today: Proceedings, 5, 2018, 83988405, https://doi.org/10.1016/j.matpr.2017.11.534

19.KC, B., FARUK, O., AGNELLI, J.A., LEAO, A., TJONG, J., SAIN, M., Sisal-glass fiber hybrid biocomposite: optimization of injection molding parameters using Taguchi method for reducing shrinkage, Composites Part A-applied Science and Manufacturing, 83, 2016, 152-159.

https://doi.org/10.1016/j.compositesa.2015.10.034

20.JUNG, J. T., LEE, B. K., Numerical analysis of mold deflection including plastic melt flow during injection molding, Transactions of the Korean Society of Mechanical Engineers A, 38(7), 2014, 719725, https://doi.org/10.3795/KSME-A.2014.38.7.719

21.KURTARAN, H., ERZURUMLU, T., Efficient warpage optimization of thin shell plastic parts using response surface methodology and genetic algorithm, International Journal of Advanced Manufacturing Technology, 27(5), 2006, 468-472, https://doi.org/10.1007/s00170-004-2321-2

22.HWANG, S. H., KIM, J. S., Injection mold design of reverse engineering using injection molding analysis and machine learning, Journal of Mechanical Science and Technology, 33, 2019, 3803-3812. https://doi.org/10.1007/s12206-019-0723-1

23.BALOG, M., MALCOVSKÝ, M., Optimization of the production process of the plastic injection molding engineering with the technology of reverse engineering application, International Scientific Journal about technologies, 1 (2), 2015, 9-12.

24.TAMAȘAG, I., BEȘLIU, I., AMARANDEI, D., Application of reverse engineering for automotive plastic components - case study, Macromolecular Symposia, 395 (1), 2021, 2000265.

https://doi.org/10.1002/masy.202000265 
25.IULANO, L., MINETOLA, P., Enhancing moulds manufacturing by mean of reverse engineering, International Journal of Advanced Manufacturing Technology, 43, 2009, 551-562.

https://doi.org/10.1007/s00170-008-1739-3

26.GUO, W., DENG, F., MENG, Z., HUA, L., MAO, H., SU, J., A hybrid back-propagation neural network and intelligent algorithm combined algorithm for optimizing microcellular foaming injection molding process parameters, Journal of Manufacturing Processes, 50, 2020, 528-538.

https://doi.org/10.1016/j.jmapro.2019.12.020

27.MARTOWIBOWO, S. Y., KASWADIK, A., Optimization and simulation of plastic injection process using genetic algorithm and moldflow, Chinese Journal of Mechanical Engineering, 30, 2017, 398-406, https://doi.org/10.1007/s10033-017-0081-9

28.AZZOUNI, M., DEMERS, V., DUFRESNE, L., Mold filling simulation and experimental investigation of metallic feedstock used in low-pressure powder injection molding, International Journal of Material Forming, 14, 2021, 961-972, https://doi.org/10.1007/s12289-021-01612-0

29.GIM, J., RHEE, B. O., Generation mechanism of gloss defect for high-glossy injection-molded surface, Korea-Australia Rheology Journal, 32 (3), 2020, 183-194.

https://doi.org/10.1007/s13367-020-0018-1

30.ALTAN, M., Reducing shrinkage in injection moldings via the Taguchi, ANOVA and neural network methods, Materials and Design, 31, 2010, 599-604.

https://doi.org/10.1016/j.matdes.2009.06.049

$\overline{\text { Manuscript received: } 29.04 .2021}$ 